\title{
Age- and Dose-Specific Anticonvulsant Action of Bumetanide in Immature Rats
}

\author{
P. MARE ̌̌ \\ Department of Developmental Epileptology, Institute of Physiology, Academy of Sciences of the \\ Czech Republic, Prague, Czech Republic
}

Received September 29, 2009

Accepted November 26, 2009

\begin{abstract}
Summary
GABA exhibits depolarizing action in the immature neurons due to high intracellular activity of chloride ions. It is maintained by cation-chloride cotransporter NKCC1 which is present in immature brain. Bumetanide is a specific inhibitor of this cotransporter. We studied possible anticonvulsant activity of bumetanide in pentylenetetrazol-induced seizures in three age groups of rat pups ( 7,12 , and 18 days old). Pretreatment with bumetanide (0.2-1 mg/kg i.p.) resulted in dose-dependent decrease of incidence of the tonic phase of generalized tonicclonic seizures in 12-day-old rats only. No effect was observed in younger and older animals. Higher dose of bumetanide $(2.5 \mathrm{mg} / \mathrm{kg}$ ) did not affect tonic convulsions but, on the contrary, decreased latencies of generalized seizures in 12-day-old animals. Lack of marked anticonvulsant effect is probably due to relative maturity of neurons in the brainstem where the generator of generalized seizures is localized. Age- and dosespecific suppression of the tonic phase needs further analysis.
\end{abstract}

\section{Key words}

Chloride transporter • GABA • Pentylenetetrazol • Ontogeny • Rat

\section{Corresponding author}

P. Mareš, Institute of Physiology ASCR, Vídeňská 1083, CZ-14220 Prague 4, Czech Republic. E-mail: maresp@biomed.cas.cz

Main inhibitory system in the brain is using gamma-aminobutyric acid (GABA) as a transmitter. Among the two basic types of GABA receptors ionotropic GABA-A receptors are more numerous than metabotropic GABA-B receptors. When supramolecular complex of GABA-A receptor is activated, anionic channel is opened and chloride ions can flow into neurons. An increased permeability for chloride ions results in hyperpolarization of neuronal membrane, i.e. to inhibitory action (for review see Möhler et al. 2005). This is valid in mature neurons where intracellular activity of $\mathrm{Cl}^{-}$is low and $\mathrm{KCC} 2$ cation-chloride cotransporter pumping $\mathrm{Cl}^{-}$from cells into extracellular space is active. On the other hand, immature neurons have low (if any) activity of this transporter but they possess a NKCC1 transporter working in the opposite direction. Therefore activation of GABA-A receptors in immature neurons results in depolarization instead of hyperpolarization and GABA exerts an excitatory action (Ben-Ari 2002). The two cation-chloride cotransporters develop in opposite directions: NKCC1 activity decreases whereas activity of KCC2 increases with maturation (Payne et al. 2003). It was recently demonstrated that an inhibitor of NKCC1 transporter bumetanide exhibits anticonvulsant action in at least two seizure models in immature rats (kainic acidinduced seizures - Dzhala et al. 2005; rapid hippocampal kindling - Mazarati et al. 2009) as well as in vitro hippocampal slices (Dzhala et al. 2005) and two intact connected hippocampi preparation (Khalilov et al. 2003, Kilb et al. 2007). Failure of anticonvulsant activity of bumetanide in some in vitro models demonstrated specificity of this action (Kilb et al. 2007). Because of this specificity we decided to examine bumetanide effects in another in vivo model - pentylenetetrazol(PTZ)induced seizures. Two types of seizures (minimal clonic and generalized tonic-clonic) with different generators and development can be elicited by this drug (Velíšek et 
al. 1992).

Experiments were performed on three age groups of male albino rats of the Wistar strain $-7,12$ and 18 days old. The animals were taken from the nest immediately before the start of the experiment and their body temperature was maintained by means of a pad heated to $34{ }^{\circ} \mathrm{C}$ (temperature in the nest) during the whole experiment. This experiment was approved by Animal Care and Use Committee of the Institute of Physiology to be in agreement with Animal Protection Law of the Czech Republic as well as with European Community Council directives 86/609/EEC.

Bumetanide was dissolved in dimethylsulfoxide (1 $\mathrm{mg}$ in $0.5 \mathrm{ml}$ ) and immediately before administration was diluted with $1.5 \mathrm{ml}$ of distilled water. It was injected intraperitoneally in doses of $0.2,0.5,1$ and $2.5 \mathrm{mg} / \mathrm{kg}$. Control animals received $25 \%$ dimethylsulfoxide in a volume corresponding to the highest dose of bumetanide. Each age and dose group consisted from 8 animals. Twenty minutes later pentylenetetrazol (PTZ) was administered subcutaneously in a dose of $100 \mathrm{mg} / \mathrm{kg}$. Both drugs were supplied by Sigma (St. Louis, MO).

The rats were observed in individual cages for 30 min after PTZ injection. Incidence, pattern and latency of seizures and all other behavioral phenomena were registered. Severity of seizures was quantified with a 5-point scale (Pohl and Mareš 1987). Incidence of generalized tonic-clonic and generalized clonic seizures was statistically evaluated by Fisher's exact test, latencies by one-way ANOVA with post-hoc pairwise comparison by Holm-Sidak's test (SigmaStat ${ }^{\circledR}$ SPSS). $\mathrm{P}<0.05$ was taken as significant.

The first sign of PTZ action was increased locomotion with frequent sniffing. All but one 18-day-old rats in the group with the $2.5-\mathrm{mg} / \mathrm{kg}$ dose of bumetanide exhibited generalized seizures (Fig. 1). A complete sequence of generalized tonic-clonic seizures was observed in all 7-day-old rats with the exception of one animal with the highest dose of bumetanide where the tonic phase was missing. Tonic phase was suppressed by bumetanide in 12-day-old rats. This effect increased with the dose of bumetanide up to $1 \mathrm{mg} / \mathrm{kg}$ (7 out of 8 rats exhibited only generalized clonic seizures), the highest dose had less expressed effect. No effects on seizure pattern were observed in 18-day-old rats. Minimal clonic seizures (normally preceding generalized tonic-clonic seizures in 18-day-old and older rats) were only exceptionally present in control as well as pretreated animals.
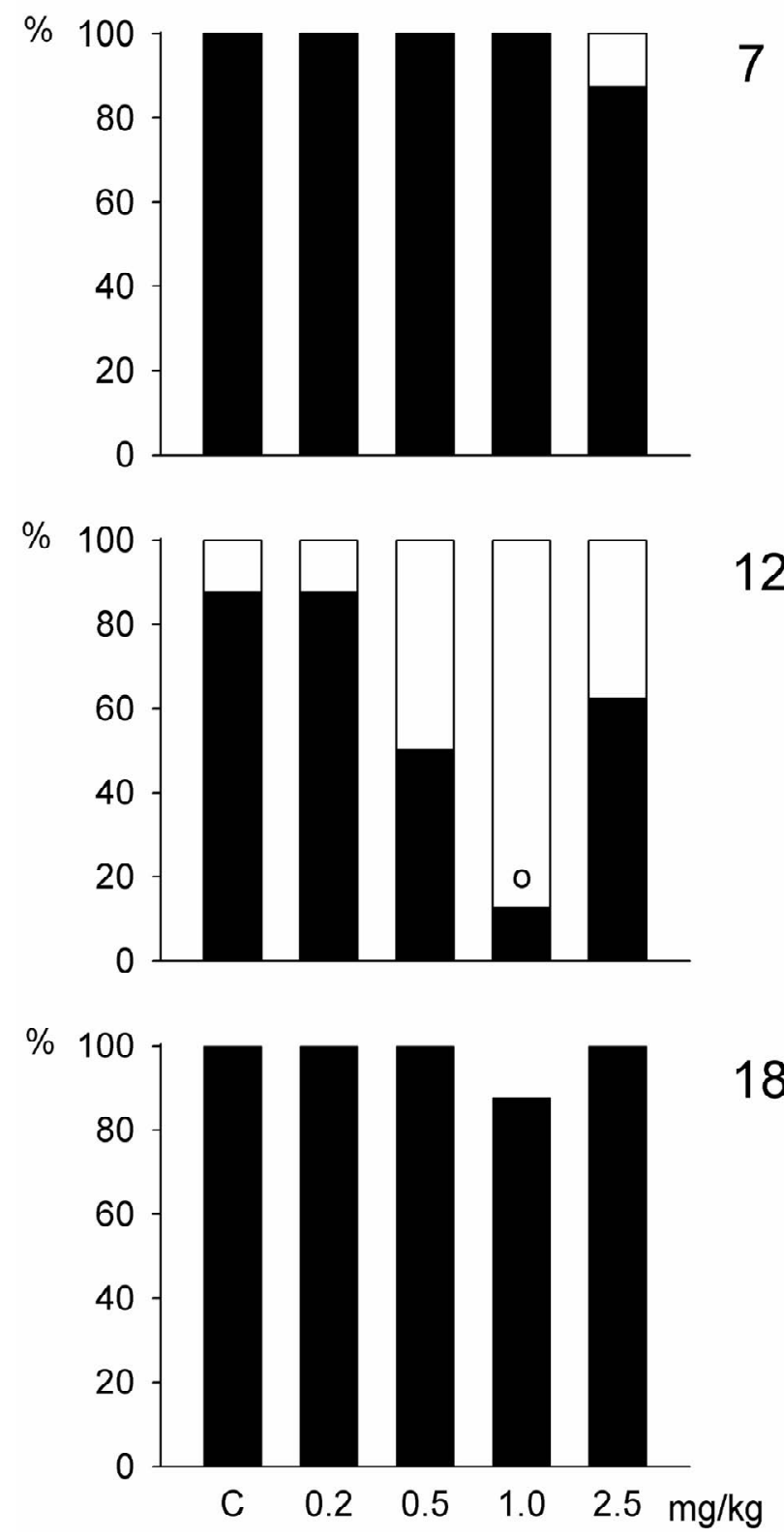

Fig. 1. Incidence of seizures in three age groups of rats; from top to bottom - 7-, 12- and 18-day-old animals. Black parts of columns represent generalized tonic-clonic seizures, white parts generalized clonic seizures (i.e. tonic phase is missing). Abcissae: doses of bumetanide, $\mathrm{C}$ means controls; ordinates: percentage of rats exhibiting seizures. o denotes a significant suppression of the tonic phase.

Seizure severity reflected above mentioned seizure pattern, i.e. presence or absence of the tonic phase (Fig. 2). The only significant decrease in comparison with controls was found after the $1-\mathrm{mg} / \mathrm{kg}$ dose in 12-day-old rats.

Latencies of generalized seizures were never prolonged (Fig. 2). On the contrary, the $2.5-\mathrm{mg} / \mathrm{kg}$ dose of bumetanide resulted in significant shortening of latencies in 12-day-old animals. Mixed anti- and 
proconvulsant effects of bumetanide were demonstrated in whole hippocampus preparation from newborn mice. Bumetanide affected differently not only epileptiform activity in various models but also individual epileptic phenomena in the same model (Kilb et al. 2007, Nardou et al. 2009).
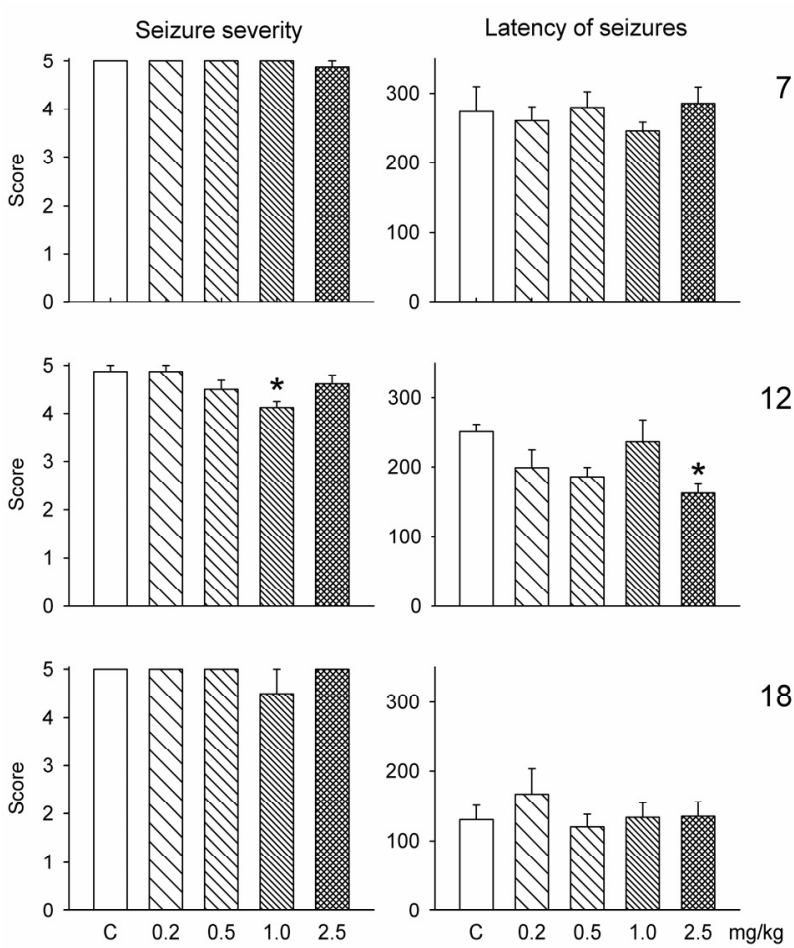

Fig. 2. Severity (left column) and latencies (right column) of seizures in 7-, 12- and 18-day-old rats (from top to bottom) presented as means \pm S.E.M. Abscissae: doses of bumetanide; ordinates in the left column: seizure severity scored according to the 5-point scale; in the right column: latencies in seconds. Asterisks denote a significant difference in comparison with the control group.

Our experiments demonstrated only an isolated anticonvulsant effect of bumetanide in 12-day-old rats where the tonic phase of generalized seizures was suppressed. A proconvulsant action - shortening of latencies of seizures - was observed in the same age group with the high dose of bumetanide. Failure of bumetanide in our experiments is probably due to the localization of generators of generalized tonic-clonic seizures. Browning and Nelson (1985) localized the generator of these seizures into the brainstem; descending part of reticular formation, i.e. the most important structure in regulation of muscle tonus, is a hot candidate. Maturation of the brain generally follows caudo-rostral gradient, therefore brainstem should be mature very early.
In addition, centers governing breathing and circulation are localized in the brainstem reticular formation and these centers must be mature at latest at a moment of birth. To explain specific suppression of the tonic phase of generalized seizures in 12-day-old but not in younger and older rats detailed data on generation of the tonic and clonic phases are needed. Failure of minimal clonic seizures in 18-day-old rats was surprising but it appeared also in control group with administration of dimethylsulfoxide. Nearly all 18-day-old rats injected with saline or without any pretreatment exhibit regularly this type of seizures (25 out of 27 animals in control groups from recent studies - e.g. Mareš 2008a,b); therefore this effect has to be ascribed to dimethylsulfoxide.

Bumetanide is a loop diuretic used in adult and pediatric nephrology (Eades and Christensen 1998); its action in kidney influences water and electrolyte composition in the whole body. A decrease of extracellular space in the brain was described after bumetanide and/or furosemide administration. This change can substantially influence normal as well as pathological (epileptic) activity and should be taken into account in experiments with loop diuretics (Schwartzkroin et al. 1998).

According to the literary data bumetanide represents a potential anticonvulsant drug specific not only for neonatal seizures (first clinical case was recently published by Kahle et al. 2009) but also for long-lasting epileptic activity which may result in an increased intracellular $\mathrm{Cl}^{-}$activity as demonstrated in vitro in slices from adult rodents (Khalilov et al. 2003) and from temporal lobe of epileptic patients (Huberfeld et al. 2007). Another possible use of bumetanide in epileptic syndromes in infancy is potentiation of action of anticonvulsant drugs with GABAergic mechanism of action (Dzhala et al. 2007). Further studies are necessary to specify possible clinical use of this promising drug.

\section{Conflict of Interest}

There is no conflict of interest.

\section{Acknowledgements}

This study was supported by grant No.S501210509 of the Grant Agency of the Academy of Sciences of the Czech Republic, and by projects No. LC-554 and AV0Z50110509. 


\section{References}

BEN-ARI Y: Excitatory actions of GABA during development: the nature of the nurture. Nature Rev Neurosci 3: 728739, 2002.

BROWNING RA, NELSON DK: Variation in threshold and pattern of electroshock-induced seizures in rats depending on site of stimulation. Life Sci 37: 2205-2211, 1985.

DZHALA V, TALOS DM, SDRULLA DA, BRUMBACK AC, MATHEWS GC, BENKE TA, DELPIRE E, JENSEN FE, STALEY KJ: NKCC1 transporter facilitates seizures in the developing brain. Nature Medicine 11: $1205-$ 1213, 2005.

DZHALA V, BRUMBACK AC, STALEY KJ: Bumetanide enhances phenobarbital efficacy in a neonatal seizure model. Ann Neurol 63: 222-235, 2007.

EADIE SK, CHRISTENSEN ML: The clinical pharmacology of loop diuretics in the pediatric patient. Pediat Nephrol 12: 603-616, 1998.

HUBERFELD G, WITTNER L, CLEMENCEAU S, BAULAC M, KAILA K, MILES R, RIVERA C: Perturbed chloride homeostasis and GABAergic signaling in human temporal lobe epilepsy. J Neurosci 27: 9866-9873, 2007.

KHALILOV I, HOLMES GL, BEN-ARI Y: In vitro formation of a secondary epileptogenic mirror focus by interhippocampal propagation of seizures. Nature Neurosci 6: 1079-1083, 2003.

KILB W, SINNING A, LUHMANN HJ: Model-specific effects of bumetanide on epileptiform activity in the in vitro intact hippocampus of the newborn mouse. Neuropharmacology 53: 524-533, 2007.

MAREŠ P: Anticonvulsant action of GABA-B receptor agonist SKF97541 differs from that of baclofen. Physiol Res 57: 789-792, 2008a.

MAREŠ P: AMN 082, an agonist of mGluR7, exhibits mixed anti and proconvulsant effects in developing rats. Physiol Res 57: 969-972, $2008 \mathrm{~b}$.

MAZARATI A, SHIN D, SANKAR R: Bumetanide inhibits rapid kindling in neonatal rats. Epilepsia 50: 2117-2122, 2009.

MÖHLER H, FRITSCHY JM, VOGT K, CRESTANI F, RUDOLPH U: Pathophysiology and pharmacology of GABA(A) receptors. Handb Exp Pharmacol 169: 225-247, 2005.

NARDOU R, BEN-ARI Y, KHALILOV I: Bumetanide, an NKCC1 antagonist, does not prevent formation of epileptogenic focus but blocks epileptic focus seizures in immature rat hippocampus. J Neurophysiol 101: 2878-2888, 2009.

PAYNE JA, RIVERA C, VOIPIO J, KAILA K: Cation-chloride co-transporters in neuronal communication, development and trauma. Trends Neurosci 26: 199-206, 2003.

POHL M, MAREŠ P: Flunarizine influences metrazol-induced seizures in developing rats. Epilepsy Res 1: 302-305, 1987.

SCHWARTZKROIN PA, BARABAN SC, HOCHMAN DW: Osmolarity, ionic flux, and changes in brain excitability. Epilepsy Res 32: 275-285, 1998.

VELÍŠEK L, KUBOVÁ H, POHL M, STAŇKOVÁ L, MAREŠ P, SCHICKEROVÁ R: Pentylenetetrazol-induced seizures in rats: an ontogenetic study. Naunyn-Schmiedeberg's Arch Pharmacol 346: 588-591, 1992. 